\title{
A phase II study of Osimertinib for patients with radiotherapy-naïve CNS metastasis of non-small cell lung cancer: treatment rationale and protocol design of the OCEAN study (LOGIK 1603/WJOG 9116L)
}

Kazushige Wakuda ${ }^{1 *} \mathbb{D}$, Hiroyuki Yamaguchi², Hirotsugu Kenmotsu', Minoru Fukuda ${ }^{3}$, Masafumi Takeshita ${ }^{4}$, Takayuki Suetsugu ${ }^{5}$, Keisuke Kirita ${ }^{6}$, Noriyuki Ebi ${ }^{7}$, Osamu Hataji ${ }^{8}$, Satoru Miura ${ }^{9}$, Kenji Chibana ${ }^{10}$, Isamu Okamoto ${ }^{11}$, Kenichi Yoshimura ${ }^{12}$, Kazuhiko Nakagawa ${ }^{13}$, Nobuyuki Yamamoto ${ }^{14}$ and Kenji Sugio ${ }^{15}$

\begin{abstract}
Background: Patients with activating epidermal growth factor receptor (EGFR) mutations are highly responsive to EGFR-tyrosine kinase inhibitors (TKIs). However, it has been reported that approximately $15-30 \%$ of patients treated with EGFR-TKIs experience central nervous system (CNS) progression, and patients with EGFR mutations exhibit a higher incidence of brain metastasis than those without such mutations. The efficacy of osimertinib for treating CNS metastasis has been reported, but its efficacy for CNS metastasis in radiotherapy-naïve patients is unclear.

Methods: In the present prospective two-cohort phase II trial, 65 patients (T790M cohort, 40 patients; first-line cohort, 25 patients) with radiotherapy-naive CNS metastasis of EGFR mutation-positive non-small cell lung cancer (NSCLC) will be included. Patients will be treated once-daily with osimertinib $80 \mathrm{mg}$. The primary endpoint is the response rate of brain metastasis as assessed using the PAREXEL criteria. Key secondary endpoints are progressionfree survival and the response rate of brain metastasis as assessed using the RECIST criteria. We will exploratorily analyze the relationships of the blood concentration of osimertinib with its efficacy against brain metastasis of NSCLC and the accumulation of osimertinib in cerebrospinal fluid and evaluate tumor-derived DNA from plasma specimens for mutations in EGFR and other genes. Recruitment, which in October 2016, is ongoing.
\end{abstract}

Discussion: Although previous reports revealed the efficacy of osimertinib for CNS metastasis, these reports only involved subgroup analysis, and the efficacy of osimertinib for patients with previously untreated CNS metastasis remains unclear. The OCEAN study is the only trial of osimertinib for patients with untreated brain metastasis of NSCLC. This study should provide novel data about osimertinib. If the results of the OCEAN study are positive, then avoidance of radiotherapy will be recommended to patients harboring EGFR mutations and brain metastasis.

\footnotetext{
* Correspondence: k.wakuda@scchr.jp

'Division of Thoracic Oncology, Shizuoka Cancer Center Hospital, 1007 Shimonagakubo Nagaizumi-cho Suntou-gun, Shizuoka 411-8777, Japan

Full list of author information is available at the end of the article
}

(c) The Author(s). 2020 Open Access This article is licensed under a Creative Commons Attribution 4.0 International License, which permits use, sharing, adaptation, distribution and reproduction in any medium or format, as long as you give appropriate credit to the original author(s) and the source, provide a link to the Creative Commons licence, and indicate if changes were made. The images or other third party material in this article are included in the article's Creative Commons licence, unless indicated otherwise in a credit line to the material. If material is not included in the article's Creative Commons licence and your intended use is not permitted by statutory regulation or exceeds the permitted use, you will need to obtain permission directly from the copyright holder. To view a copy of this licence, visit http://creativecommons.org/licenses/by/4.0/ The Creative Commons Public Domain Dedication waiver (http://creativecommons.org/publicdomain/zero/1.0/) applies to the data made available in this article, unless otherwise stated in a credit line to the data. 
(Continued from previous page)

Trial registration: UMIN identifier: UMIN000024218 (date of initial registration: 29 September 2016). jRCT identifier: jRCTs071180017 (date of initial registration: 13 February 2019).

Keywords: Non-small cell lung cancer, EGFR T790M, CNS metastasis, Brain metastasis, Osimertinib

\section{Background}

Patients with activating epidermal growth factor receptor $(E G F R)$ mutations are highly responsive to EGFRtyrosine kinase inhibitors (TKIs). However, it has been reported that approximately $15-30 \%$ of patients treated with EGFR-TKIs experience central nervous system (CNS) progression, and patients with EGFR mutations exhibit a higher incidence of brain metastasis than those without such mutations [1-3]. Although radiotherapy (RT), such as whole-brain radiotherapy (WBRT) and stereotactic radiotherapy, is a standard treatment for CNS metastasis, the median survival time of patients receiving WBRT is only 4-8 months $[4,5]$. It has also been reported that the risk of cognitive dysfunction was increased by WBRT. Thus, a need exists for new treatment strategies other than RT.

A majority of patients treated with EGFR-TKIs experience disease progression after 10-12 months, and approximately $50 \%$ of patients develop acquired resistance caused by the EGFR T790M mutation [6]. Osimertinib is an irreversible EGFR-TKI that selectively inhibits both EGFR-TKI-sensitizing mutations and the EGFR T790M mutation. The results of the AURA3 trial, a phase III trial comparing osimertinib with platinum and pemetrexed for patients with non-small cell lung cancer (NSCLC) harboring the EGFR T790M mutation who were previously treated with EGFR-TKIs, were reported in 2017 [7]. Osimertinib significantly prolonged progression-free survival (PFS) compared with the effects of platinum and pemetrexed (median PFS: 10.1 months versus 4.4 months, $p<$ 0.001 ), and it has emerged as the standard treatment for patients with NSCLC harboring the EGFR T790M mutation who experience disease progression during or after treatment with EGFR-TKIs. In 2018, the FLAURA trial, a phase III trial comparing osimertinib with gefitinib or erlotinib in the first-line setting for patients with EGFR mutation who had not previously received EGFR-TKIs, was reported [8]. In the study, PFS was significantly longer in the osimertinib arm than in the gefitinib/erlotinib arm (median PFS: 18.9 months versus 10.2 months, $\mathrm{p}<0.001$ ). Osimertinib is currently used in the first-line setting for patients harboring EGFR-sensitive mutations.

It was reported that osimertinib displayed greater penetration into the brain than rociletinib or gefitinib in a preclinical model [9]. Osimertinib is expected to have efficacy in patients with CNS metastasis; indeed, a subgroup analysis of patients with CNS metastasis has been reported [10]. In that report, pooled data from two phase II trials of osimertinib in the treatment of patients with NSCLC harboring the EGFR T790M mutation (AURA extension and AURA2) were analyzed. Of the 411 patients who participated in these trials, 128 had CNS metastasis, and 50 had one or more measurable CNS lesions. The rate of confirmed CNS responses to osimertinib was $54 \%$ in patients with measurable CNS metastasis. Nineteen patients with brain metastasis had already been treated with RT within 6 months before the first dose, and the CNS response in this subgroup was $32 \%$. Conversely, in 31 patients who received RT more than 6 months before the first drug dose or who did not receive RT, the rate of CNS responses to osimertinib was $68 \%$. However, in a subgroup analysis of AURA 3, the CNS response rate of osimertinib for patients who were treated with RT within 6 months before randomization was 64\% [11]. Contrarily, the CNS response for patients who did not receive RT within 6 months before randomization was $34 \%$. In these two subgroup analyses, the efficacy of osimertinib for CNS metastasis in patients who did not receive RT was controversial. Because it was assumed that RT might have influenced the efficacy of osimertinib in these studies, the efficacy of osimertinib for CNS metastasis in patients who did not previously receive $\mathrm{RT}$ is unclear. A prior multi-institutional retrospective analysis found that patients with brain metastasis who underwent stereotactic radiosurgery (SRS) before EGFR-TKI therapy exhibited better overall survival (OS) than their counterparts who received EGFRTKIs before SRS [12]. The efficacy of osimertinib for brain metastasis in patients who did not receive RT is controversial, and it is unclear whether EGFR-TKIs should be administered without brain RT to such patients. Thus, a trial assessing the efficacy of osimertinib for patients with untreated CNS metastasis is needed.

\section{Methods \\ Study design}

The OCEAN study is a multicenter, single-arm phase II study. The overall objective is to evaluate the efficacy of osimertinib for untreated CNS metastasis. Figure 1 provides an overview of the OCEAN study scheme. Patients will orally receive osimertinib at $80 \mathrm{mg}$ once daily until progression, death, or withdrawal of consent to participate in this study. 


\begin{tabular}{|c|c|c|c|}
\hline \multicolumn{4}{|c|}{ Single-arm phase II trial } \\
\hline $\begin{array}{ll}\checkmark & \text { NSCLC } \\
\checkmark & \text { EGFR mutation positive }{ }_{1} \\
\checkmark & \text { Untreated brain metastasis } \% 2 \\
\checkmark & \text { ECOG PS 0-2 } \\
\checkmark & \text { At least } 20 \text { years old }\end{array}$ & $\begin{array}{l}\text { ort }(\mathrm{N}=40) \\
\text { d with EGFR-TK } \\
790 \mathrm{M} \text {-positive } \\
\text { hort }(\mathrm{N}=25) \\
\text { ted with EGFR-TK } \\
\text { or postoperative }\end{array}$ & & Osimertinib: $80 \mathrm{mg}$ once daily \\
\hline \multicolumn{4}{|c|}{$\begin{array}{l}\text { Primary endpoint: Response rate of brain metastasis assessed using PAREXEL criteria } \\
\text { Secondary endpoints: Progression-free survival, Overall survival } \\
\text { Response rate of brain metastasis assessed using RECIST criteria }\end{array}$} \\
\hline \multirow[t]{2}{*}{ Exploratory endpoint } & \multicolumn{3}{|c|}{ Sampling time } \\
\hline & Before treatment & Day 22 & Date of disease progression \\
\hline Blood concentration of osimertinib & & 0 & \\
\hline Cerebrospinal fluid concentration of osimertinib & & if possible & \\
\hline EGFR mutation in plasma specimen cfDNA & O & O & $\bigcirc$ \\
\hline $\begin{array}{l}\text { Gene alteration of plasma specimen cfDNA } \\
\text { assessed using Guardant } 360\end{array}$ & $\bigcirc$ & $\bigcirc$ & $\bigcirc$ \\
\hline
\end{tabular}

Fig. 1 Study schema

Before registration in this trial, contrast-enhanced computed tomography (CT) of the chest and abdomen and contrast-enhanced magnetic resonance imaging (MRI) of the brain with a slice thickness of less than 3 $\mathrm{mm}$ are required. CT and MRI will be performed every 6 weeks in the first year after the date of registration and every 3 months thereafter.

The OCEAN study is being conducted in compliance with the principles of the Declaration of Helsinki, and it was approved by the central review board of Clinical Research Network Fukuoka. This trial is registered in the University Hospital Medical Information Network Trials Registry (UMIN000024218) and Japan Registry of Clinical Trials (jRCTs071180017).

\section{Eligibility criteria}

The main patient inclusion and exclusion criteria are shown in Table 1. Initially, the OCEAN study aimed to include only patients with NSCLC harboring the EGFR T790M mutation who experienced disease progression during or after treatment with EGFR-TKIs. However, patient recruitment was slow because osimertinib has been approved for use in the first-line setting. In addition, it is also important to assess the efficacy of osimertinib for untreated CNS metastasis in EGFR-TKI-naïve patients. We amended the study protocol and established a first- line cohort including previously untreated patients harboring EGFR-sensitive mutations regardless of the presence of the EGFR T790M mutation.

\section{Study endpoints}

The initial primary endpoints of the OCEAN study at the start of study enrollment were the response rate of brain metastasis (BMRR) as assessed using the PAREXEL criteria and PFS (https://www.parexel.com/ files/5214/0422/3830/MI_Brain_Metastases_White_

Paper_JUN_14.pdf). We established the first-line cohort to assess the efficacy of osimertinib for untreated CNS metastasis in EGFR-TKI-naïve patients, and thus, PFS was changed to a secondary endpoint. The PAREXEL criteria represent a tool for assessing brain metastasis, and they have recently been used in several trials. In these criteria, the target lesion of brain metastasis has a size of $5 \mathrm{~mm}$ or more in the long axis. Some reports indicated that the size of brain metastases was significantly smaller for patients with mutant EGFR than in those with wild-type EGFR, and we believe that the PAREXEL criteria are also useful for evaluating evaluate small brain metastases [3, 13]. A maximum of five lesions in the brain will be chosen, and the sum of their diameters will be calculated (sum of the longest axes of all target brain lesions). Non-target lesions include all measurable 
Table 1 Key inclusion and exclusion criteria

\begin{tabular}{|c|c|c|}
\hline \multicolumn{3}{|c|}{ Key inclusion criteria } \\
\hline & T790M cohort & First-line cohort \\
\hline$\checkmark$ & \multicolumn{2}{|c|}{ Histologically or cytologically confirmed non-small cell lung cancer } \\
\hline$\checkmark$ & \multicolumn{2}{|c|}{$\begin{array}{l}\text { Confirmed EGFR mutations (exon } 19 \text { deletion, exon } 21 \text { L858R point } \\
\text { mutation) }\end{array}$} \\
\hline$\checkmark$ & $\begin{array}{l}\text { Radiological disease progression following } \\
\text { first- or second-generation EGFR-TKls }\end{array}$ & $\begin{array}{l}\text { Previously untreated } \\
\text { with EGFR-TKls }\end{array}$ \\
\hline$\checkmark$ & \multicolumn{2}{|l|}{$\begin{array}{l}\text { Confirmed EGFR T790M mutation detected } \\
\text { from tumor or plasma sample after disease } \\
\text { progression from prior treatment }\end{array}$} \\
\hline$\checkmark$ & & $\begin{array}{l}\text { Stage IV or } \\
\text { postoperative relapse }\end{array}$ \\
\hline$\checkmark$ & \multicolumn{2}{|c|}{$\begin{array}{l}\text { Patients must have a brain metastasis lesion of } 5 \mathrm{~mm} \text { or more } \\
\text { in size in the long axis irrespective of the presence of extracrania } \\
\text { metastases } \\
\text { Patients with brain metastasis requiring emergent therapy are } \\
\text { excluded }\end{array}$} \\
\hline$\checkmark$ & \multicolumn{2}{|l|}{ No prior radiation therapy for brain metastasis } \\
\hline$\checkmark$ & \multicolumn{2}{|c|}{ Patients aged at least 20 years at the time of informed consent } \\
\hline$\checkmark$ & \multicolumn{2}{|l|}{ ECOG performance status $0-2$} \\
\hline$\checkmark$ & \multicolumn{2}{|l|}{ Adequate organ function } \\
\hline$\checkmark$ & \multicolumn{2}{|c|}{ Mean corrected QT interval not exceeding $471 \mathrm{~ms}$} \\
\hline$\checkmark$ & \multicolumn{2}{|c|}{ Written informed consent obtained from the patient } \\
\hline \multicolumn{3}{|c|}{ Key exclusion criteria } \\
\hline$\checkmark$ & \multicolumn{2}{|c|}{$\begin{array}{l}\text { Symptomatic brain metastasis requiring radiation therapy or surgical } \\
\text { resection }\end{array}$} \\
\hline$\checkmark$ & \multicolumn{2}{|l|}{ Severe complications } \\
\hline$\checkmark$ & \multicolumn{2}{|c|}{$\begin{array}{l}\text { Presence of active double cancers (synchronous cancers and } \\
\text { metachronous cancers with a disease-free interval of no more than } \\
5 \text { years) }\end{array}$} \\
\hline$\checkmark$ & \multicolumn{2}{|c|}{$\begin{array}{l}\text { Prior treatment with anti-PD-1, anti-PD-L1, anti-CD137, and anti- } \\
\text { CTLA-4 antibody }\end{array}$} \\
\hline$\checkmark$ & \multicolumn{2}{|l|}{ Pregnancy or planned or expected pregnancy } \\
\hline$\checkmark$ & \multicolumn{2}{|l|}{ Lactation in women } \\
\hline$\checkmark$ & \multicolumn{2}{|c|}{$\begin{array}{l}\text { History of interstitial lung disease, drug-induced interstitial lung dis- } \\
\text { ease, and radiation pneumonitis requiring steroid treatment }\end{array}$} \\
\hline$\checkmark$ & \multicolumn{2}{|c|}{ Presence of symptomatic superior vena cava syndrome } \\
\hline$\checkmark$ & \multicolumn{2}{|c|}{ Presence of psychiatric disorder or mental symptoms } \\
\hline$\checkmark$ & \multicolumn{2}{|c|}{$\begin{array}{l}\text { History of hypersensitivity to osimertinib and any excipients of } \\
\text { osimertinib }\end{array}$} \\
\hline
\end{tabular}

Abbreviations: EGFR Epidermal growth factor receptor, TKI Tyrosine kinase inhibitor, ECOG Eastern Cooperative Oncology Group, PD-1 Programmed cell death-1, PD-L1 Programmed cell death-ligand 1, CD Cluster designation, CTLA4 Cytotoxic T-lymphocyte antigen-4

lesions not chosen as target lesions and lesions with a long axis of $<5 \mathrm{~mm}$. There will be no limit on the number of non-target lesions. The assessment of brain metastasis response is similar to that using the RECIST criteria [14]. The response of each target lesion will be classified as complete response (CR), partial response $(\mathrm{PR})$, stable disease (SD), progressive disease (PD), or not evaluable (NE). The response of each non-target lesion will be classified as $\mathrm{CR}$, non-CR/non-PD, $\mathrm{PD}$, or
NE. Key secondary endpoints of the OCEAN study include PFS, the overall response rate (ORR) as assessed using the RECIST criteria, BMRR as assessed using the RECIST criteria, brain metastasis-related PFS, OS, BMRR in the first-line cohort, and PFS in the first-line cohort. PFS is defined as the time from the date of registration to that of death or disease progression, whichever occurs first. Brain metastasis-related PFS is defined as the time from the date of registration to that of death or brain metastasis progression, whichever occurs first. OS is defined as the time from the date of registration to that of death.

To investigate the relationship between the concentration of osimertinib and the treatment effect, we are exploratorily assessing the blood concentration of osimertinib at day 22, which considered to represent steady state [15]. We are also determining the cerebrospinal fluid concentration of osimertinib to analyze its penetration into this fluid. It is also necessary to measure its blood concentration. Blood specimens will thus be collected once 22 days after osimertinib administration. Cerebrospinal fluid is collected on a voluntary basis. The blood and cerebrospinal fluid concentrations of osimertinib are being assessed using HB-13-050 and HB-13-081 (HPLC-MS/MS). To determine whether the EGFR C797S mutation is present before progression, we are also evaluating tumor-derived DNA for EGFR mutations, including the C797S point mutation, in plasma specimens. Plasma specimens for EGFR mutation analysis are collected three times: before treatment, 22 days after the administration of osimertinib, and on the date of diagnosis of progressive disease. In the first-line cohort, we will also evaluate tumor-derived DNA by the Guardant 360 liquid biopsy for gene alterations in plasma specimens to simultaneously analyze the mechanism of acquired resistance to osimertinib and the EGFR mutation status. Guardant 360 assesses point mutations (SNVs) and deletion variants (Indels) in 74 genes, amplification in 18 genes, and fusions in 6 genes. The cut-off for mutant variants is $\geq 0.04 \%$ for SNVs, Indels, and fusions and $\geq 2.18$ copies for amplifications.

\section{Statistical considerations}

The primary endpoint of the OCEAN study is BMRR as assessed using the PAREXEL criteria in the full analysis set population, excluding the first-line cohort. To estimate BMRR, we refer to the results of the AURA trial [16]. In this trial, ORR was $61 \%$ (95\% confidence interval $[C I]=52-70 \%)$. We will consider osimertinib effective if similar efficacy is observed in patients with untreated brain metastasis. On the basis of the lower limit of the 95\% CI of ORR in the AURA trial, we set a threshold value of BMRR of $50 \%$. We also set an expected value of $70 \%$ based on the upper limit of the $95 \%$ CI of ORR in 
the AURA trial. First, based on one-sided alpha $=0.05$ and power $=0.9$, the sample size for the OCEAN study was calculated to be 60 , considering the possibility of patient withdrawal. However, we amended our statistical hypothesis from power $=0.9$ to 0.8 because of the slow accrual rate. The sample size was changed to 37 , and the amended sample size was calculated to be 40 considering dropouts. Considering the threshold and expected values of BMRR of 55 and $80 \%$, respectively, in the firstline cohort, the sample size of the first-line cohort was calculated to be 25 considering dropouts at one-sided alpha $=0.05$ and power $=0.8$.

\section{Discussion}

Although previous reports described the efficacy of osimertinib for treating CNS metastasis, these studies only involved subgroup analysis, and the efficacy of osimertinib for patients with previously untreated CNS metastasis remained unclear. The OCEAN study has several limitations. First, whether brain metastases had the EGFR T790M mutation was unclear because EGFR T790M was assessed using extracranial tissue or plasma samples. However, CSF sampling is only performed in patients with suspected meningeal carcinomatosis prior to osimertinib in clinical practice; therefore, requiring CSF sampling before enrollment would be difficult. We believe that the OCEAN study is valuable because its study design is suitable for clinical practice. Second, the OCEAN study was a single-arm phase II study. Patients treated with radiotherapy prior to osimertinib might have experience better treatment efficacy than those treated with osimertinib prior to radiotherapy. Magnuson et al. performed a retrospective analysis and found that upfront EGFR-TKI therapy and deferral of radiotherapy was associated with inferior OS in patients with NSCLC harboring EGFR mutations and CNS metastasis [12]. However, patients who were not treated with EGFR-TKI after radiotherapy were excluded. Because radiotherapy might prevent osimertinib, which has been shown to be effective for patients with EGFR mutations, and because the risk of cognitive dysfunction is increased by WBRT, we considered that comparison of osimertinib and radiotherapy in patients with CNS metastasis would be difficult. To our knowledge, the OCEAN study is the only trial of osimertinib for patients with untreated brain metastasis that has been initiated to date. This study should provide novel data about osimertinib. If the results of this study meet the primary endpoint, then it will be recommended that patients with brain metastasis harboring EGFR mutations forgo RT.

\section{Abbreviations}

BMRR: Response rate of brain metastasis; CNS: Central nervous system; CT: Computed tomography; EGFR: Epidermal growth factor receptor: MRI: Magnetic resonance imaging; NSCLC: Non-small cell lung cancer;
ORR: Overall response rate; OS: Overall survival; PFS: Progression-free survival; RT: Radiation therapy; SRS: Stereotactic radiosurgery; TKI: Tyrosine kinase inhibitors; WBRT: Whole-brain radiation therapy

\section{Acknowledgements}

Data management and monitoring for the study are being conducted by the Clinical Research Support Center Kyushu.

\section{Authors' contributions}

All authors contributed to the design of the study. KW, HY, HK, and MF are the principal investigators of the study. MT, TS, KK, NE, OH, SM, KC, IO, KN,

$\mathrm{NY}$, and KS will be involved in participant recruitment. KY was responsible for statistical analysis. All authors have read and approved the manuscript.

\section{Funding}

The OCEAN study was funded by AstraZeneca. The funders provided for the necessary financial resources to cover the personnel costs need to proceed the OCEAN study.

\section{Availability of data and materials}

Not applicable.

\section{Ethics approval and consent to participate}

The OCEAN study is being conducted in compliance with the principles of the Declaration of Helsinki, and it was approved by the central review board of Clinical Research Network Fukuoka. Written informed consent is obtained from all participants.

Consent for publication

Not applicable.

\section{Competing interests}

$\mathrm{KK}, \mathrm{HY}, \mathrm{HK}, \mathrm{FM}, \mathrm{KK}, \mathrm{OH}, \mathrm{SM}, \mathrm{IO}, \mathrm{KY}, \mathrm{KN}$, and $\mathrm{NY}$ have received personal fees and / or grants from AstraZeneca.

\section{Author details}

${ }^{1}$ Division of Thoracic Oncology, Shizuoka Cancer Center Hospital, 1007 Shimonagakubo Nagaizumi-cho Suntou-gun, Shizuoka 411-8777, Japan. ${ }^{2}$ Department of Respiratory Medicine, Nagasaki University Graduate School of Biomedical Sciences, 1-7-1 Sakamoto, Nagasaki 852-8501, Japan.

${ }^{3}$ Department of Respiratory Medicine, Nagasaki University Graduate School of Biomedical Sciences and Clinical Oncology Center, Nagasaki University Hospital, 1-7-1 Sakamoto, Nagasaki 852-8501, Japan. ${ }^{4}$ Department of Respiratory Medicine, Kitakyushu Municipal Medical Center, 2-1-1 Bashaku, Kokurakita-ku, Kitakyushu, Fukuoka 802-0077, Japan. ${ }^{5}$ Department of Respiratory Medicine, Sendai Medical Association Hospital, 4107-7 Nagatoshi-cho, Satsumasendai, Kagoshima 895-0005, Japan. ${ }^{6}$ Department of Thoracic Oncology, National Cancer Center Hospital East, 6-5-1 Kashiwanoha, Kashiwa, Chiba 277-8577, Japan. ${ }^{7}$ Department of Respiratory Medicine, lizuka Hospital, 3-83 Yoshiomachi, lizuka, Fukuoka 820-8505, Japan. ${ }^{8}$ Department of Respiratory Medicine, Matsusaka Municipal Hospital Respiratory Center, 1550 Tonomachi, Matsusaka, Mie 515-8544, Japan. ${ }^{9}$ Department of Internal Medicine, Niigata Cancer Center Hospital, 2-15-3 Kawagishi-cho, Chuo-ku, Niigata 951-8566, Japan. ${ }^{10}$ Department of Respiratory Medicine, National Hospital Organization, Okinawa National Hospital, 3-20-14 Ganeko, Ginowan, Okinawa 901-2214, Japan. ${ }^{11}$ Research Institute for Diseases of the Chest, Graduate School of Medical Sciences, Kyushu University, 3-1-1 Maidashi, Higashi-ku, Fukuoka 812-8582, Japan. ${ }^{12}$ Department of Biostatistics, Innovative Clinical Research Center, Kanazawa University Hospital, Takara-machi, Kanazawa, Ishikawa 920-8641, Japan. ${ }^{13}$ Department of Medical Oncology, Kindai University Faculty of Medicine, 377-2 Ohno-higashi, Osaka-Sayama, Osaka 589-8511, Japan. ${ }^{14}$ Internal Medicine III, Wakayama Medical University, 811-1 Kimiidera, Wakayama 641-8509, Japan.

${ }^{15}$ Department of Thoracic and Breast Surgery, Oita University Faculty of Medicine, 1-1 Idaigaoka, Hasama-machi, Yufu, Oita 879-5593, Japan. 
Received: 2 January 2020 Accepted: 16 April 2020

Published online: 01 May 2020

\section{References}

1. Omuro AM, Kris MG, Miller VA, Franceschi E, Shah N, Milton DT, Abrey LE. High incidence of disease recurrence in the brain and leptomeninges in patients with nonsmall cell lung carcinoma after response to gefitinib. Cancer. 2005;103:2344-8

2. Lee YJ, Choi HJ, Kim SK, Chang J, Moon JW, Park IK, Kim JH, Cho BC Frequent central nervous system failure after clinical benefit with epidermal growth factor receptor tyrosine kinase inhibitors in Korean patients with nonsmall-cell lung cancer. Cancer. 2010;116:1336-43.

3. Iuchi $T$, Shingyoji M, Itakura M, Yokoi S, Moriya $Y$, Tamura H, Yoshida $Y$ Ashinuma H, Kawasaki K, Hasegawa Y, Sakaida T, lizasa T. Frequency of brain metastases in non-small-cell lung cancer, and their association with epidermal growth factor receptor mutations. Int J Clin Oncol. 2015;20:674-9.

4. Andrews DW, Scott CB, Sperduto PW, Flanders AE, Gaspar LE, Schell MC, Werner-Wasik M, Demas W, Ryu J, Bahary JP, Souhami L, Rotman M, Mehta MP, Curran WJ Jr. Whole brain radiation therapy with or without stereotactic radiosurgery boost for patients with one to three brain metastases: phase III results of the RTOG 9508 randomised trial. Lancet. 2004;363:1665-72

5. Sperduto PW, Shanley R, Luo X, Andrews D, Werner-Wasik M, Valicenti R, Bahary JP, Souhami L, Won M, Mehta M. Secondary analysis of RTOG 9508, a phase 3 randomized trial of whole-brain radiation therapy versus WBRT plus stereotactic radiosurgery in patients with 1-3 brain metastases; poststratified by the graded prognostic assessment (GPA). Int J Radiat Oncol Biol Phys. 2014:90:526-31.

6. Sequist LV, Waltman BA, Dias-Santagata D, Digumarthy $S$, Turke AB, Fidias $P$, Bergethon K, Shaw AT, Gettinger S, Cosper AK, Akhavanfard S, Heist RS, Temel J, Christensen JG, Wain JC, Lynch TJ, Vernovsky K, Mark EJ, Lanuti M, lafrate AJ, Mino-Kenudson M, Engelman JA. Genotypic and histological evolution of lung cancers acquiring resistance to EGFR inhibitors. Sci Transl Med. 2011;3:75ra26.

7. Mok TS, Wu YL, Ahn MJ, Garassino MC, Kim HR, Ramalingam SS, Shepherd FA, He Y, Akamatsu H, Theelen WS, Lee CK, Sebastian M, Templeton A, Mann H, Marotti M, Ghiorghiu S. Papadimitrakopoulou VA; AURA3 Investigators. Osimertinib or platinum-Pemetrexed in EGFR T790M-positive lung Cancer. N Engl J Med. 2017;376:629-40.

8. Soria JC, Ohe Y, Vansteenkiste J, Reungwetwattana T, Chewaskulyong B, Lee KH, Dechaphunkul A, Imamura F, Nogami N, Kurata T, Okamoto I, Zhou C, Cho BC, Cheng Y, Cho EK, Voon PJ, Planchard D, Su WC, Gray JE, Lee SM, Hodge R, Marotti M, Rukazenkov Y, Ramalingam SS, Investigators FLAURA. Osimertinib in untreated EGFR-mutated advanced non-small-cell lung Cancer. N Engl J Med. 2018:378:113-25.

9. Ballard P, Yates JW, Yang Z, Kim DW, Yang JC, Cantarini M, Pickup K, Jordan A, Hickey M, Grist M, Box M, Johnström P, Varnäs K, Malmquist J, Thress KS, Jänne PA, Cross D. Preclinical comparison of Osimertinib with other EGFRTKIs in EGFR-mutant NSCLC brain metastases models, and early evidence of clinical brain metastases activity. Clin Cancer Res. 2016;22:5130-40.

10. Goss G, Tsai CM, Shepherd FA, Ahn MJ, Bazhenova L, Crinò L, de Marinis F, Felip E, Morabito A, Hodge R, Cantarini M, Johnson M, Mitsudomi T, Jänne PA, Yang JC. CNS response to osimertinib in patients with T790M-positive advanced NSCLC: pooled data from two phase II trials. Ann Oncol. 2017;29: 687-93.

11. Wu YL, Ahn MJ, Garassino MC, Han JY, Katakami N, Kim HR, Hodge R, Kaur P, Brown AP, Ghiorghiu D, Papadimitrakopoulou VA, Mok TSK. CNS efficacy of Osimertinib in patients with T790M-positive advanced non-small-cell lung Cancer: data from a randomized phase III trial (AURA3). J Clin Oncol. 2018:36:2702-9.

12. Magnuson WJ, Lester-Coll NH, Wu AJ, Yang TJ, Lockney NA, Gerber NK, Beal K, Amini A, Patil T, Kavanagh BD, Camidge DR, Braunstein SE, Boreta LC, Balasubramanian SK, Ahluwalia MS, Rana NG, Attia A, Gettinger SN, Contessa $J N, Y u$ JB, Chiang VL. Management of Brain Metastases in tyrosine kinase inhibitor-naive epidermal growth factor receptor-mutant non-small-cell lung Cancer: a retrospective multi-institutional analysis. J Clin Oncol. 2017;35: 1070-7.

13. Sekine A, Kato T, Hagiwara E, Shinohara T, Komagata T, Iwasawa T, Satoh H, Tamura K, Kasamatsu T, Hayashihara K, Saito T, Takahashi H, Ogura T. Metastatic brain tumors from non-small cell lung cancer with EGFR mutations: distinguishing influence of exon 19 deletion on radiographic features. Lung Cancer. 2012;77:64-9.

14. Therasse P, Arbuck SG, Eisenhauer EA, Wanders J, Kaplan RS, Rubinstein L, Verweij J, Van Glabbeke M, van Oosterom AT, Christian MC, Gwyther SG. New guidelines to evaluate the response to treatment in solid tumors. European Organization for Research and Treatment of Cancer, National Cancer Institute of the United States, National Cancer Institute of Canada. J Natl Cancer Inst. 2000;92:205-16.

15. Planchard D, Brown KH, Kim DW, Kim SW, Ohe Y, Felip E, Leese P, Cantarini M, Vishwanathan K, Jänne PA, Ranson M, Dickinson PA. Osimertinib Western and Asian clinical pharmacokinetics in patients and healthy volunteers: implications for formulation, dose, and dosing frequency in pivotal clinical studies. Cancer Chemother Pharmacol. 2016;77:767-76.

16. Janne PA, Yang JC, Kim DW, Planchard D, Ohe Y, Ramalingam SS, Ahn MJ, Kim SW, Su WC, Horn L, Haggstrom D, Felip E, Kim JH, Frewer P, Cantarini M, Brown KH, Dickinson PA, Ghiorghiu S, Ranson M. AZD9291 in EGFR inhibitor-resistant non-small-cell lung cancer. N Engl J Med. 2015;372:1689-99.

\section{Publisher's Note}

Springer Nature remains neutral with regard to jurisdictional claims in published maps and institutional affiliations.
Ready to submit your research? Choose BMC and benefit from:

- fast, convenient online submission

- thorough peer review by experienced researchers in your field

- rapid publication on acceptance

- support for research data, including large and complex data types

- gold Open Access which fosters wider collaboration and increased citations

- maximum visibility for your research: over $100 \mathrm{M}$ website views per year

At $\mathrm{BMC}$, research is always in progress.

Learn more biomedcentral.com/submissions 